\title{
Effect of spectacle use and accommodation on myopic progression: final results of a three-year randomised clinical trial among schoolchildren
}

\author{
OLAVI PÄRSSINEN, ${ }^{1}$ ELINA HEMMINKI, ${ }^{2}$ AND ANNELI KLEMETTI ${ }^{1}$ \\ From the 'Department of Ophthalmology of the Central Hospital of Central Finland, Jyväskylä Finland, and the \\ ${ }^{2}$ Department of Public Health, University of Helsinki, Finland
}

SUMMARY Two hundred and forty mildly myopic schoolchildren aged 9-11 years were randomly allocated to three treatment groups and the progression of myopia was followed-up for three years. The treatment groups were: (1) minus lenses with full correction for continuous use (the reference group), (2) minus lenses with full correction to be used for distant vision only, and (3) bifocal lenses with $+1.75 \mathrm{D}$ addition. Three-year refraction values were received from 237 children. The differences in the increases of the spherical equivalents were not statistically significant in the right eye, but in the left eye the change in the distant use group was significantly higher $(-1.87 \mathrm{D})$ than in the continuous use group $(-1.46 \mathrm{D})(\mathrm{p}=0 \cdot 02$, Student's $t$ test $)$. There were no differences between the groups in regard to school achievement, accidents, or satisfaction with glasses. In all three groups the more the daily close work done by the children the faster was the rate of myopic progression (right eye: $r=0 \cdot 253$, $p=0.0001$, left eye: $r=0 \cdot 267, p=0 \cdot 0001$ ). Myopic progression did not correlate positively with accommodation, but the shorter the average reading distance of the follow-up time the faster was the myopic progression (right eye: $r=0 \cdot 222, p=0.0001$, left eye: $r=0.255, p=0.001)$. It seems that myopic progression is connected with much use of the eyes in reading and close work and with short reading distance but that progression cannot be reduced by diminishing accommodation with bifocals or by reading without spectacles.

There are different opinions about the effect of spectacles on the progression of myopia. Those who believe that accommodation increases myopic progression usually recommend spectacles to be worn only for distant vision, and they often prescribe undercorrected lenses ${ }^{1-3}$ or bifocals. ${ }^{45}$ Others think that spectacles should be worn continuously. ${ }^{67}$ Some authors suggest it makes no difference whether spectacles are devised for the special needs of children and worn either continuously or for distant vision only. ${ }^{89}$ These studies have been reviewed previously. ${ }^{1011}$

The purpose of this article is to report the final three-year results of a randomised trial comparing the effects of three different styles of correcting myopia among schoolchildren. The types of correction were fully corrected lenses for continuous use, for distant use only, and bifocals. In addition the

Correspondence to $O$ Pärssinen, MD, Kannaksenk. 5, 40600 Jyväskylä, Finland. relation between myopic progression and accommodation, reading distance, and time spent on in reading and close work is examined.

\section{Material and methods}

Material and methods have been published in detail previously. ${ }^{10}$ "Schoolchildren from the third and fifth grades of basic school who were referred to the outpatient clinic of the Central Hospital of Central Finland because of suspected myopia were considered for inclusion in the study. Their mean age was 10.9 years (range $8 \cdot 8-12.8 \mathrm{yr}$ ), and they were recruited without selection while one of us (OP) was working in the outpatient clinic. The eye examination was carried out by the same ophthalmologist before inclusion in the study and at every control visit. To control possible observer bias the last examination was also carried out on 84 children by another ophthalmologist (AK) who did not know the group 
assignments of the children. She assessed the refraction whenever she was available when the children came to the clinic. Refraction was measured about 45-60 minutes after administration of two drops of $1 \%$ cyclopentolate hydrochloride.

After exclusions the 240 children (spherical equivalents -0.35 to $-3.0 \mathrm{D}$ ) were allocated to one of the three treatment groups by means of random sex-stratified codes in sealed envelopes. Before randomisation the children were asked whether they would like to participate in the study, and all agreed.

All the children received full correction for distant vision. The children allocated to the first group (termed continuous use group) were advised to use their glasses continuously. The children in the second group (termed distant use group) were advised to use them only when accurate distant vision was needed. The children in the third group (termed the bifocal group) received bifocals with $1.75 \mathrm{D}$ near addition. The bifocals were the Coburn straight top 28, with a diameter of $65 \mathrm{~mm}$. The top of the addition was fitted 2-3 mm below the centre of the pupil. All the children were advised to buy untinted lenses.

The child and the accompanying parent were given a questionnaire asking about background characteristics and habits. ${ }^{10}$ The questionnaire was given also during the control visits. At the time of inclusion in the study the three groups were similar in regard to most of the background characteristics, and the few small differences did not systematically favour any of the groups.

The children were invited three times by letter at one-year intervals to attend for follow-up examinations. The refraction values were adjusted for the varying follow-up times so that the last refraction was multiplied by $3 \times 365$ and divided by the exact number of follow-up days.

After allocation one of the boys in the continuous use group was excluded from comparison with the other treatment groups when we found that his sister has been included previously in a different group. Two children moved from the area, and their refraction values could not be obtained. The refraction of one further child was obtained from the files of his ophthalmologist.

The usual reading distance was measured by Clement Clark's accommodometer during every control visit. The average accommodation in reading was estimated from these readings and from the averages of the spherical equivalents of the right eye in two consecutive examinations. The following formulae were used to calculate accommodation between two control visits:

Continuous use: $\mathrm{ACC}=\left(100 / \mathrm{R}_{1}+100 / \mathrm{R}_{2}\right): 2+\left(\mathrm{SFD}_{2}-\mathrm{SFD}_{1}\right): 2$

Distant use: $A C C=\left(100 / R_{1}+100 / R_{2}\right): 2+\left(S_{2} D_{2}+S F D_{1}\right): 2$

Bifocals: $A C C=\left(100 / R_{1}+100 / R_{2}\right): 2+\left(S F D_{2}-S F D_{1}\right): 2-1 \cdot 75$
ACC $=$ accommodation, $R_{1}$ and $R_{2}=$ reading distances in two consecutive visits, $S F D_{1}$ and $\mathrm{SFD}_{2}=$ spherical equivalents of the right eye in two consecutive visits.

The average reading distance and accommodation for the whole follow-up was calculated from the consecutive values for annual reading distance and accommodation. The information concerning the amount of time spent on reading and other close work, on watching TV, and on outdoor activities was obtained from the questionnaire at the last examination.

The differences between the means of follow-up time, age, height, weight, reading distance, accommodation, refraction, and time spent on different activities for the three treatment groups were tested by Student's $t$ test with the continuous age group as a reference group. The differences between the groups in compliance and in treatment problems were analysed by the $\chi^{2}$ test. The associations between the refraction change and accommodation, reading distance and daily time spent on reading and close work, and outdoor activities and watching television were analysed by means of Pearsson's product moment correlation coefficients.

\section{Results}

The follow-up times varied between 2.0 and $5 \cdot 1$ years, and in $95 \%$ of cases it was between 3.0 and $3 \cdot 1$ years. The means were similar in the different treatment groups (Table 1). There were no significant differences between the treatment groups in mean age at the end of the study. The bifocal group was $2 \mathrm{~cm}$ taller and $3.5 \mathrm{~kg}$ heavier than the continuous use group.

Compliance with the treatment was quite good (Table 2). Compliance was determined according to the children's reports of their use of spectacles during the previous year. In the continuous use and bifocal groups those children who had worn their spectacles continuously were classified as compliant. In all groups those wearing their spectacles at various times were classified as partly compliant. In the distant use group those wearing spectacles for distant vision

Table 1 Background characteristics of treatment groups at the end of the study (means and SD)

\begin{tabular}{lccc}
\hline & Distant use & Continuous use & Bifocals \\
\hline Number of boys & 38 & 40 & 40 \\
Number of girls & 41 & 39 & 39 \\
Mean follow-up (yr) & $3.0(0 \cdot 1)$ & $3 \cdot 0(0 \cdot 1)$ & $3 \cdot 0(0 \cdot 3)$ \\
Mean age (yr) & $13.9(1 \cdot 0)$ & $14 \cdot 0(1 \cdot 1)$ & $14 \cdot 0(1 \cdot 0)$ \\
Mean height (cm) & $161(10)$ & $162(8 \cdot 3)$ & $164(8 \cdot 1)$ \\
Mean weight (kg) & $49 \cdot 2(10 \cdot 1)$ & $49 \cdot 0(8 \cdot 7)^{*}$ & $52 \cdot 5(9 \cdot 6)$
\end{tabular}

${ }^{*} \mathrm{p}<0 \cdot 05, t$ test, continuous use group as the reference group. 
Table 2 Compliance and problems with the treatment

\begin{tabular}{lrll}
\hline & $\begin{array}{l}\text { Distant } \\
\text { use }\end{array}$ & $\begin{array}{l}\text { Continuous } \\
\text { use }\end{array}$ & Bifocals \\
\hline Compliant (\%) & 89 & 79 & 76 \\
Partly compliant (\%) & 6 & 18 & 21 \\
$\begin{array}{l}\text { Non-compliant (\%) } \\
\text { Good satisfaction (\%) }\end{array}$ & 5 & 3 & 3 \\
$\begin{array}{l}\text { Glasses broken or lost } \\
\text { at least once during the } \\
\text { last year (\%) }\end{array}$ & 19 & 25 & 78 \\
$\begin{array}{l}\text { at least once during the } \\
\text { follow-up (\%) }\end{array}$ & 37 & 42 & 28 \\
$\begin{array}{c}\text { Accidents during the last year } \\
\text { (\%) }\end{array}$ & 10 & 12 & 12 \\
\hline
\end{tabular}

only, or only occasionally, were classified as compliant, and those wearing them constantly were classified as non-compliant. The proportions of compliant children somewhat increased in the continuous use and distant use groups during the follow-up.

During the first year the bifocal lenses were changed to monofocals for four children. No such changes were needed after the first year. One of the four whose lenses were changed moved to another locality during the first year and the results of only her first year refraction were received. In the case of one child the use of bifocals was discontinued because of increasing exophoria, and two children regarded the bifocals as inconvenient and ugly and discontinued their use.

Children were relatively satisfied with their spectacles according to the answers given in the questionnaire (Table 2). In each treatment group there were two to four children who were otherwise satisfied but did not see clearly enough, and they were also classified as satisfied. In the bifocal group six children considered the glasses ugly or the line between the segments disturbing. Otherwise the

Table 3 Reading distance, accommodation, and time spent in different activities among treatment groups during the last year (mean and $S D$ )

\begin{tabular}{|c|c|c|c|c|c|}
\hline & $\begin{array}{l}\text { Distant } \\
\text { use }\end{array}$ & & $\begin{array}{l}\text { Continuous } \\
\text { use }\end{array}$ & & Bifocals \\
\hline $\mathbf{n}$ & 79 & & 79 & & 79 \\
\hline Reading distance $(\mathrm{cm})$ & $27(5)$ & & $27(5)$ & & $28(5)$ \\
\hline $\begin{array}{l}\text { Accommodation in near } \\
\text { work (D) }\end{array}$ & $1 \cdot 0(1 \cdot 0)$ & $* *$ & $3 \cdot 5(1.0)$ & $* *$ & $1 \cdot 7(0 \cdot 8)$ \\
\hline $\begin{array}{l}\text { Daily time used for } \\
\text { reading and other near } \\
\text { work (h) }\end{array}$ & $3 \cdot 1(1 \cdot 0)$ & & $3.4(1.0)$ & & $3.2(0.9)$ \\
\hline $\begin{array}{l}\text { Daily time used for } \\
\text { outdoor activities (h) }\end{array}$ & $2 \cdot 8(1 \cdot 4)$ & & $3 \cdot 0(1 \cdot 2)$ & $* *$ & $2 \cdot 4(1 \cdot 1)$ \\
\hline $\begin{array}{l}\text { Daily time spent watching } \\
\text { TV (h) }\end{array}$ & $2 \cdot 1(0 \cdot 9)$ & $* *$ & $2 \cdot 5(0 \cdot 9)$ & & $2.4(1.0)$ \\
\hline
\end{tabular}

${ }^{* *} \mathrm{p}<0.01, t$ test, continuous use group as the reference group. reasons for dissatisfaction were similar in the three groups. For example, glasses were regarded as unpractical, and they were a nuisance in sports and other activities. The degree of satisfaction did not significantly change during the follow-up. The glasses were broken or lost somewhat more often in the continuous use group than in the other two groups.

There were no significant differences between the groups in accidents during the last three months or during the last year. School averages were also similar and varied between 7.9 and 8.0 (in Finland grades are given from 4 to 10 ).

There were no differences in reading distance between the groups, but the calculated mean accommodation for the whole follow-up in reading was significantly less in the distant use and bifocal groups than in the continuous use group (Table 3 ). The time spent daily on reading and near work was similar in all the treatment groups. Children in the bifocal group reported spending less time daily on sports and outdoor activities than those in the continuous use group. The watching of television was less in the distant use group than in the continuous use group.

The increase in myopia measured both in terms of change since the beginning of the study and group means was greatest in the distant use group in the left eye (Table 4). In the right eye the differences between the groups were not statistically significant. The increase in astigmatism was also somewhat smaller in the continuous use group than in the others, but the differences were not statistically significant.

The increase in myopia was faster among girls than among boys. The same was seen in all the treatment groups, though there were no refraction differences between boys and girls at the beginning of the study. The time spent daily on reading and near work was nearly the same for both boys and girls (boys $3.2 \mathrm{~h}$, and girls $3.3 \mathrm{~h}$ ). Boys spent more time on sports and outdoor activities than girls (boys $3.0 \mathrm{~h}$ and girls $2 \cdot 5 \mathrm{~h})$.

The reliability of refraction readings is given in Table 5. The ophthalmologist AK, who did not know the group assignment of the subjects, found spherical equivalents which were $-0.11 \mathrm{D}$ to $-0.27 \mathrm{D}$ more myopic than the respective values of ophthalmologist OP. The differences did not favour any of the treatment groups and least of all the continuous use group. The differences were not statistically significant. A possible explanation of the differences is the time between the two examinations. The children usually had to wait 15-30 minutes after refraction in the case of OP, so that the effect of the cycloplegic had diminished, so that the refractions done by AK were perhaps more myopic.

The shorter the average reading distance of the 
Table 4 Refraction in different treatment groups, means in dioptres (and SD)

\begin{tabular}{|c|c|c|c|c|c|}
\hline & & $\begin{array}{l}\text { Distant } \\
\text { use }\end{array}$ & & $\begin{array}{l}\text { Continuous } \\
\text { use }\end{array}$ & Bifocal \\
\hline \multicolumn{6}{|c|}{$\begin{array}{l}\text { Change of spherical } \\
\text { equipment since entry }\end{array}$} \\
\hline \multicolumn{4}{|c|}{ Boys and girls right eye $-1.76(1.0)$} & $-1.48(0 \cdot 9)$ & $-1.67(0.9)$ \\
\hline & left eye & $-1 \cdot 88(1 \cdot 0)$ & ** & $-1.46(0.9)$ & $-1.58(0.9)$ \\
\hline \multirow[t]{2}{*}{ Boys } & right eye & $-1.60(1.0)$ & & $-1 \cdot 36(0 \cdot 9)$ & $-1.39(0 \cdot 7)$ \\
\hline & left eye & $-1.73(0 \cdot 9)$ & $*$ & $-1 \cdot 37(0 \cdot 8)$ & $-1 \cdot 29(0 \cdot 7)$ \\
\hline Girls & $\begin{array}{l}\text { right eye } \\
\text { left eye }\end{array}$ & $\begin{array}{l}-1.92(1.0) \\
-2.02(1.0)\end{array}$ & & $\begin{array}{l}-1.59(1.0) \\
-1.54(1.0)\end{array}$ & $\begin{array}{l}-1.96(1.0) \\
-1.89(1.0)\end{array}$ \\
\hline \multicolumn{6}{|c|}{ Change of astigmatism } \\
\hline \multicolumn{2}{|c|}{ Boys and girls right eye } & $\begin{array}{l}-0.23(0.4) \\
-0.23(0.3)\end{array}$ & & $\begin{array}{l}-0 \cdot 14(0 \cdot 4) \\
-0 \cdot 15(0 \cdot 3)\end{array}$ & $\begin{array}{l}-0.23(0.4) \\
-0.22(0.4)\end{array}$ \\
\hline \multicolumn{6}{|c|}{$\begin{array}{l}\text { Spherical equivalent at } \\
\text { the end of the study }\end{array}$} \\
\hline \multirow{2}{*}{\multicolumn{2}{|c|}{ Boys and girls right eye }} & $-3 \cdot 11(1 \cdot 2)$ & & $-2 \cdot 92(1 \cdot 1)$ & $-3 \cdot 17(1 \cdot 1)$ \\
\hline & & $-3 \cdot 32(1 \cdot 1)$ & $*$ & $-2 \cdot 94(1 \cdot 1)$ & $-3 \cdot 10(1 \cdot 2)$ \\
\hline \multirow[t]{2}{*}{ Boys } & right eye & $-2.95(1.2)$ & & $-2 \cdot 83(1 \cdot 2)$ & $-2 \cdot 86(1 \cdot 0)$ \\
\hline & left eye & $-3.20(1 \cdot 1)$ & & $-2 \cdot 92(1 \cdot 1)$ & $-2 \cdot 76(1 \cdot 1)$ \\
\hline \multirow[t]{2}{*}{ Girls } & right eye & $-3 \cdot 27(1 \cdot 2)$ & & $-3.01(1.0)$ & $-3.48(1 \cdot 3)$ \\
\hline & left eye & $-3.43(1 \cdot 1)$ & & $-2.97(1.0)$ & $-3.45(1.2)$ \\
\hline
\end{tabular}

${ }^{*} \mathrm{p}<0 \cdot 5,{ }^{* *} \mathrm{p}<0 \cdot 01, t$ test, continuous use group as the reference group.

follow-up time the faster was the rate of myopic progression of the right eye (Table 6), though the bifocal group were an exception. About the same correlations were true also with reading distance of the last year and with the left eye. The correlation between accommodation and myopic progression was significant only in the distant use group; the less the accommodation the faster was myopic progression. This correlation, however, depends on the calculation formula; the higher the myopia and myopic progression the more was the accommodation value reduced when reading was done without spectacles.

The more the time spent on reading and close work the faster was the rate of myopic progression. The correlation between myopic progression and outdoor

Table 5 Spherical equivalents of 84 children in the last control visit studied by two ophthalmologists, means in dioptres (and $S D$ ) are shown. Number of children: 25 in the distant use group, 27 in the continuous use group, and 32 in the bifocal group

\begin{tabular}{|c|c|c|c|}
\hline & $\begin{array}{l}\text { Ophthalmologist } \\
\text { OP }\end{array}$ & $\begin{array}{l}\text { Ophthalmologist } \\
A K\end{array}$ & Difference \\
\hline \multicolumn{4}{|l|}{ Right eye } \\
\hline distant use & $-2.83(0.9)$ & $-3.07(1.1)$ & -0.24 \\
\hline continuous use & $-3 \cdot 22(1 \cdot 0)$ & $-3.33(0.9)$ & $-0 \cdot 11$ \\
\hline bifocal & $-3 \cdot 26(1 \cdot 4)$ & $-3 \cdot 42(1 \cdot 3)$ & $-0 \cdot 16$ \\
\hline \multicolumn{4}{|l|}{ Left eye } \\
\hline distant use & $-3.00(0.9)$ & $-3 \cdot 21(1 \cdot 0)$ & -0.21 \\
\hline continuous use & $-3 \cdot 14(0 \cdot 9)$ & $-3.32(0.9)$ & $-0 \cdot 18$ \\
\hline bifocal & $-3 \cdot 15(1 \cdot 4)$ & $-3 \cdot 38(1 \cdot 2)$ & -0.23 \\
\hline
\end{tabular}

Table 6 The Pearson's product moment correlation coefficients $(r)$ and $p$ values $(p)$ between myopic progression in the right eye and the average reading distance and accommodation during the whole follow-up, and the time spent daily on different activities during the last year

\begin{tabular}{|c|c|c|c|c|c|}
\hline & & $\begin{array}{l}\text { Distant } \\
\text { use } \\
(n=64-79)\end{array}$ & $\begin{array}{l}\text { Continuou } \\
\text { use } \\
(n=64-79)\end{array}$ & $\begin{array}{l}\text { Bifocal } \\
(n=60-79)\end{array}$ & $\begin{array}{l}\text { All } \\
(n=188-236)\end{array}$ \\
\hline \multirow{2}{*}{$\begin{array}{l}\text { Reading } \\
\text { distance }\end{array}$} & $\mathbf{r}$ & -0.290 & -0.278 & $-0 \cdot 105$ & -0.222 \\
\hline & $\mathrm{p}$ & 0.006 & 0.009 & $0 \cdot 187$ & $<0.001$ \\
\hline \multirow{2}{*}{$\begin{array}{l}\text { Accommoda- } \\
\text { tion }\end{array}$} & r & 0.260 & -0.073 & 0.046 & 0.114 \\
\hline & $\mathrm{p}$ & 0.019 & 0.284 & 0.363 & 0.059 \\
\hline \multirow{2}{*}{$\begin{array}{l}\text { Daily time on } \\
\text { reading and } \\
\text { near work }\end{array}$} & $\mathbf{r}$ & -0.313 & -0.287 & -0.241 & -0.253 \\
\hline & $\mathrm{p}$ & 0.003 & 0.005 & 0.016 & $<0.001$ \\
\hline \multirow{2}{*}{$\begin{array}{l}\text { Daily time on } \\
\text { outdoor } \\
\text { activities }\end{array}$} & $\mathbf{r}$ & 0.286 & $0 \cdot 139$ & 0.013 & $0 \cdot 174$ \\
\hline & $\mathrm{p}$ & 0.006 & $0 \cdot 111$ & 0.455 & 0.004 \\
\hline \multirow{2}{*}{$\begin{array}{l}\text { Daily time on } \\
\text { watching TV }\end{array}$} & $\mathbf{r}$ & -0.079 & 0.202 & 0.050 & 0.075 \\
\hline & p & $0 \cdot 246$ & 0.037 & 0.333 & 0.126 \\
\hline
\end{tabular}

activities was the opposite, but it held true only in the distant use group. The more time spent daily on watching TV, the less was the myopic progression in the continuous use group.

\section{Discussion}

The results of this three-year follow-up show that neither the use of bifocals nor avoiding the use of spectacles in reading slows down myopic progression. On the contrary myopic progression was somewhat slower among those who were advised to use spectacles all the time. In some animal experiments blurring of vision has induced myopic progression. ${ }^{12}$ It has also been suggested that astigmatism when uncorrected could induce myopic progression. ${ }^{13}$ Uncorrected myopia in cases where the use of spectacles is avoided so as to be used only for distant vision might have the same kind of effect.

In previous studies the prevalence of myopia has been shown to be connected with reading and close work. ${ }^{14-16}$ In this study the progression of myopia among myopic children was also related to much reading and close work. So it seems that not only the prevalence of myopia but also the degree of myopia is connected with the amount of reading.

During reading without spectacles the relation between accommodation and convergence is changed. There is also obviously more need of convergence and less need of accommodation. In this study there was a positive correlation between short reading distance and rapid myopic progression, but the correlation was negative or nil between myopic progression and accommodation. This result runs counter to the view that accommodation in reading is an important factor in myopic progression. ${ }^{17}$ These 
results may lend support to the theory that convergence is one reason for myopic progression, ${ }^{18}$ but the question still remains whether the short reading distance is a reason for the faster myopic progression or the consequence of higher myopia. The differences in myopic progression between the treatment groups cannot be explained by differences in the reading distances, as they were statistically the same in all the groups.

Children in the bifocal group spent somewhat less time on sports and outdoor activities than did the others. The lower segment of bifocals may disturb vision and is perhaps the reason for that finding. Why the distant use group watched TV less than the others is not clear. Previously it has been found that myopia begins earlier among girls than boys, ${ }^{19}$ and in some studies there was a higher prevalence of myopia among women than men. ${ }^{20}$ In this study the progression of myopia was faster among girls than boys in all the treatment groups, though their refractions were similar at the beginning of the study. It is difficult to say whether that difference depends on the small differences in time spent on reading and close work and on sports and outdoor activities.

On the basis of these results the continuous use of fully corrected spectacles can be recommended for myopic children. It cannot yet be stated whether the same holds true for myopic adults. To determine this we are planning a similar study with a group of lateonset myopic adults.

This study was supported by a grant from the Academy of Finland. We thank also the Instrumentarium Corporation for sharing the costs of the bifocal lenses.

\section{References}

1 Angle J, Wissmann DA. Myopia and corrective lenses. Soc Sci Med 1980; 14A: 473-9.

2 Rehm DS. The myopia myth. The truth about nearsightness and how to prevent it. Ligonier, PA, USA: International Myopia Prevention Association, 1981.
3 Tokoro T. The role of accommodation in myopia. Acta Ophthahlmol (Kbh) 1988; 185 (suppl): 153-5.

4 Roberts WL, Banford RD. Evaluation of bifocal correction techniques in juvenile myopia. (Dissertation.) Massachusetts College of Optometry, 1963.

5 Daubs J, Shotwell AJ. Optical prophylaxis for environmental myopia: an epidemilogical assessment of short-term effects. Am J Optom Physiol Opt 1983; 66: 316-20.

6 Jackson E. The control of myopia. JAMA 1935; 105: 1412-6.

7 Nugent OB. The use of base in prisms in the treatment of school myopia. West Virginia Med J 1949; 45: 103-6.

8 Miles PW. Should the myopic child wear glasses all the time? Am J Ophthalmol 1962; 53: 866-7.

9 Rubin ML, Milder B. Myopia, a treatable disease. Surv Ophthalmol 1976; 21 : 65-9.

10 Hemminki E, Pärssinen TO. Prevention of myopic progress by glasses. Study design and the first-year results of a randomized trial among school children. Am J Optom Physiol Opt 1987; 64: 611-6.

11 Pärssinen O, Hemminki E. Spectacle use, bifocals and prevention of myopic progression. The two-years results of a randomized trial among schoolchildren. Acta Ophthalmol (Kbh) 1988; suppl 185: 156-61.

12 Wiesel TN, Raviola E. Increase in axial length of the macaque monkey eye after corneal opatification. Invest Ophthalmol Vis Sci 1979; 18: 1232-6.

13 Fulton A, Hansen RM, Petersen RA. The relation of myopia and astigmatism in developing eyes. Ophthalmology 1982; 89: 298-302.

14 Tscherning M. Studien über die aetiologie der myopie. Graefes Arch Clin Exp Ophthalmol 1883; 29: 201-78.

15 Pärssinen O, Leskinen A-L, Era P, Heikkinen E. Myopia, use of eyes, and living habits among men aged 33-37 years. Acta Ophthalmol (Kbh) 1985; 63: 395-400.

16 Pärssinen $O$. Relation between refraction, education, occupation, and age among 26- and 46-year-old Finns. Am J Optom Physiol Opt 1987; 64: 136-43.

17 Sato T. Criticism of various accommodogeneous theories on school myopia. Doc Ophthalmol Proc Ser 1981; 28: 97-102.

18 Greene PR. Myopia and extraocular muscles. Doc Ophthalmol Proc Ser 1981; 28: 163-9.

19 Krause U, Krause K, Rantakallio P. Sex differences in refraction errors, up to the age of 15 . Acta Ophthalmol (Kbh) 1982; 60: 91726.

20 Sperduto RD, Seigel D, Roberts J, Rowland M. Prevalence of myopia in United States. Arch Ophthalmol 1983; 101: 405-7.

Accepted for publication 28 October 1988. 